\title{
STRUCTURE AND OIL AND GAS RESOURCES OF THE OSAGE RESERVATION, OKLAHOMA.
}

\section{INTRODUCTION.}

\author{
By David White.
}

Purpose of this report.-Responding to the imperative need for increasing to the utmost the petroleum supply of the United States, the Geological Survey, since we entered the war, has largely concentrated its investigations of oil fields in the most promising undeveloped territory, such as Wyoming and the midcontinent-Texas region, and especially in the Osage Reservation in Oklahoma.

The Osage Reservation demands particular attention at this time because (1) it contains a great acreage of unleased oil lands; (2) the productivity of the developed areas is high and well sustained; (3) anticlines and domes are numerous in the greater part of the area, and the development and tests indicate that most of the structurally favorable folds will yield oil; (4) the oil is of paraffin grade, mainly $35^{\circ}$ to $36^{\circ}$ Baumé, yielding about 23 per cent of gasoline in present practice but capable of producing over 50 per cent by the best methods; (5) pipe lines and refineries are already at hand; and (6) the Office of Indian Affairs, which administers the lands, held in common by the Osage Indians, is offering leases of hundreds of quarter sections to openly competitive bidders on advertised dates.

Between May 30, 1917, and May 19, 1918, four auctions of leases were held, offering 9,280 acres May 31, 1917, 20,000 acres November 12, 1917, 32,160 acres February 14, 1918, and 51,360 acres May 18, 1918. About 1,160,000 acres remain (August, 1918) to be leasied.

A review of the bonuses paid shows a most regrettable lack of information as to the relative values of the tracts on the part of some of the bidders and suggests that many of them had little if any geologic guidance. Although some of the oil operators had examinations made by geologists for their exclusive benefit, many tracts in which the structure is favorable to the occurrence of oil were neglected or wholly disregarded, and large bonuses were paid for other tracts that will probably never yield oil in commercial quantities. These facts 
are all the more unfortunate because the leases made at the last three sales require drilling within nine months after the date of approval of the lease. Dry holes will be drilled, even when located in accordance with the best geologic information obtainable, but they will be fewer, especially in regions like this, where the oil and gas, if present, are as a rule found in anticlines and domes. The loss of the driller in bonuses, labor, equipment, supplies, and transportation and even his loss of time and opportunity through fruitless boring in an area of distinctly unfavorable structure constitute an economic waste that affects the military efficiency of the Nation.

This report is therefore issued to supply an evident need for geologic information regarding the Osage lands. In the separate papers the most practical and immediately available conclusions reached by the geologists as to the structure and oil prospects in the townships already examined are published for the immediate use of the oil man. In preparing these papers the geologists have departed somewhat from the more formal and comprehensive style characteristic of the reports of the Survey, in order to put the data into the hands of the public at the earliest possible moment. Important studies, such as those of water relations or of the continuity and porosity of the sands-features that strongly affect and may even nearly neutralize the influence of the geologic structure in controlling the distribution of oil and gas-require considerable time and are therefore necessarily postponed for incorporation in the more detailed reports to follow.

Field examinations.-The field investigations in the Osage Reservation were conducted with the cooperation of the Office of Indian Affairs and of the commissioner for the Osage Indians. The examinations, which have been carried on for over a year by $\mathbf{K}$. C. Heald, who has had immediate charge of the work, and by the geologists who were associated with him, were interrupted in order that the office work of preparing the township maps and descriptions might be completed, but some of the geologists are now (July, 1918) still in the field. The field work, which included plane-table mapping with telescopic alidade under many hardships in addition to those of the severe winter, was carried forward with splendid teamwork and with gallant and indefatigable emulation. In recording his admiration for the esprit and high standard of this war work, done by geologists in professional civil service, the writer believes he expresses the appreciation not only of the Geological Survey but of the oil operators as well.

General features of the region.-The geographic position of the Osage Reservation, which forms Osage County in northeastern Oklahoma, is shown in Plate $I$, which also shows the distribution of the principal known oil and gas fields in the State. The reservation, or 

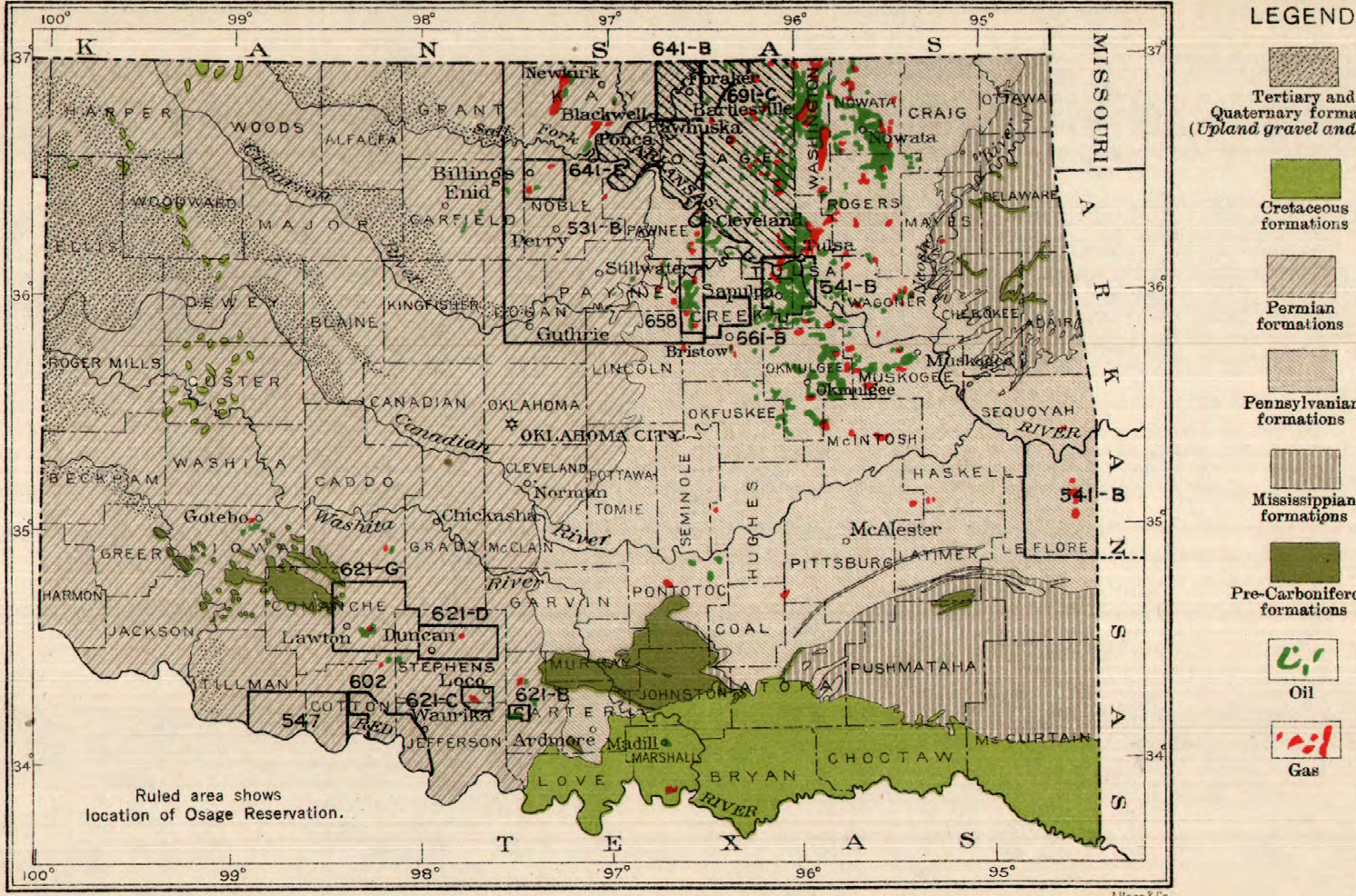

formations
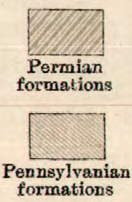

formations

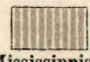

Mississippian formations

Pre-Carboniferous formations

$C_{1}^{\prime}$

is:

Gas Heavy numbers refer to numbered bulletins in which other

oil fields in Okiahoma are described 

"Nation," as it is commonly called in the region, lies in the heart of the Mid-Continent oil field. It has fair railway facilities, but its wagon roads lack much in number and quality. Three pipe lines extend to Mississippi River and eastern refineries; four carry Osage oil to Gulf ports.

Wooded ridges, mostly capped by sandstones, characterize the "east side" - that part of the reservation east of R. 7 E.-especially in the southeastern portion. Much of the "west side," very little of which is yet leased for oil, is open rolling prairie, now cattle range, with a rather deeply incised dendritic drainage system cutting bluffforming limestones. The valleys of the larger creeks are broad, covered with alluvium, and fertile. On the west the bottom lands along Arkansas River are several miles broad, heavily wooded, and in places covered with sand dunes.

All of the Osage Reservation is underlain by strata of Pennsylvanian age, which in the northwest corner are covered by the Permian. (See Pl. I.) The Pennsylvanian beds, as will be fully noted in the township descriptions, consist of shales, sandstones, and limestones. The limestones occur in the northeastern part of the reservation, but they are most prominent in the uppermost Pennsylvanian and in the Permian on the "west side"; the sandstones are more conspicuous in the central and eastern wooded ridge country, where many of them are local and lenticular. All the limestones tend to lose their distinctive character as they extend southward from the Kansas line, so that many of them can not be identified in the southern part of the reservation. The number of red beds increases in the same direction. In northern Oklahoma the Pennsylvanian thickens toward the south by the expansion of some of its formations and especially by the introduction of lower strata, due to the northward extension of the Pennsylvanian sea into the Mid-Continent embayment. The latter circumstance accounts for the presence of many lower sands that are difficult to correlate in the drill $\operatorname{logs}$, but the thickening is not marked in the Osage Reservation, where all the basal Pennsylvanian sands (mostly known as Bartlesville) are of Cherokee age.

In most of the region rock outcrops are reasonably good, but the determination of the underground structure, through the examination of the exposed formations, is very difficult and even impossible in certain areas, especially in the east-central and southern parts of the region, on account of the disappearance of some of the limestones, the irregularity in the sandstones, and the concealment of many of the intervening strata by valley wash and alluvium.

Geologic structure.-The strata in the Osage Reservation have a general westerly dip that averages about 30 feet to the mile. Actually 
the beds are bent or folded, particularly in the eastern and southern areas, into many relatively small, shallow depressions and low elevations that vary greatly in form and size and apparently have little regularity or system of arrangement. Most of these buckles or folds are not long enough in proportion to their width and are not sufficiently parallel to be described as "waves" in the beds, as will be seen by a glance at the maps.

The folding or bending of the beds is more marked on the "east side" than throughout most of the "west side" except in the southeast corner. In fact, well-developed folds are comparatively few on the "west side" and largely on this account it is probably far less important as a source of petroleum than the "east side." The increasing depth to the lower sands toward the west further detracts from the relative value of the "west side." The southeastern portion of that side will probably be found to be the best oil territory.

The faults in this region are, in general, few and of relatively slight displacement. They offer evidence of torsional stresses, mainly from the southeast. It is probable that most of them affect but little the amount of oil in the anticlines or domes.

Additional and more detailed information as to the general character of the country and its geologic features will be found in the reports by $\mathrm{Mr}$. Heald on the Foraker and Pawhuska quadrangles ${ }^{1}$ and in the valuable report on petroleum and natural gas in Oklahoma published by the State Geological Survey. ${ }^{2}$

The unit area treated in the following papers is the township, which, to permit greater detail in the delineation of key rocks and structure and greater accuracy in the location of the wells, is mapped (without topographic contours) on the scale of approximately 2 inches to the mile. The stratigraphio descriptions are confined mainly to the exposed key rocks, their intervals, convergence, etc., and the known or expected oil sands. The key rocks used in determining the structure in the township are shown only by lines marking the outcrop of the particular horizon - the base, the top, or a characteristic and easily recognized layer-used as the datum plane.

$U$ se of structure contours. - The structural features-that is, the domes, anticlines (upward folds), synclines (downward folds), and folds of other types and the faults-are shown on the maps by "structure contours." Each contour represents an imaginary line on the surface of an inclined rock stratum, connecting all points of that surface that have the same elevation. This elevation is noted

${ }^{1}$ Heald, K. C., The oil and gas geology of the Foraker quadrangle, Osage County, Okla. : U. S. Geol. Survey Bull. 641 , pp. 17-47, 1917; Geologic structure of the northwestern part of the Pawhuska quadrangle, Okla. : U. S. Geol. Survey Bull. 691, pp. 57-100, 1918 (Bull. 691-C).

${ }^{2}$ Petroleum and natural gas in Oklahoma : Oklahoma Geol. Survey Bull. 19, 2 pts., 1917. 
in terms of distance above or below some assumed datum-for example, sea level.

If the rock stratum could be stripped bare and one were to walk along the path indicated by a contour line, he would go neither uphill nor down. The difference in elevation indicated by any two succeeding contour lines is uniform. Thus the successive contour lines may represent distances of 10, 20,30, 40 feet, etc., above or below the datum plane, and the difference in elevation (in this case 10 feet) marked by adjacent contour lines is the "contour interval." Where the contour lines are close together the slope of the contoured bed is steep; where they are far apart the slope is gentle. Accordingly these lines show with approximate accuracy, by their direction and spacing, the location, shape, extent, and height or depths of the folds or wrinkles in which the strata are bent.

In order to make easier the distinction between domes and sags, or local depressions, the contour lines indicating the sides of the depressions are hachured (marked with short lines on the inner side). Howerer, an inspection of the numbers giving the elevations of the contours at once shows the progress and amount of the rise or depression of the rock surface, the height of the anticline or dome and the depth of the syncline or trough. A structure contour that passes all the way (closes) around an anticline or dome shows that the strata dip away from the axis in every direction - that is, the structure is "closed." Closing contours indicate anticlinal or (if hachured) synclinal structure. The term "closure" indicates, for a dome or anticline, the vertical distance between the lowest point on the fold through which a closing contour would pass and the highest point on the fold; for a syncline, just the reverse. It is usually stated as the vertical distance between the highest and lowest closing contours actually shown on the map, plus the contour interval, and is assigned to the side on which the next lower contour (on an anticline or dome; next higher on a syncline) would not close. For example, if the contour interval adopted is 10 feet, if the distance between the highest and lowest closing contours on a dome is 30 feet, and if the next lower contour would not close on the east the dome is said to have a closure of 40 feet on the east.

Errors in structure mapping due to convergence of strata.-It may happen that two geologists, mapping adjoining areas, have based their structure contouring on key beds which are not extensive enough to furnish a good tie between the two areas. One may have confined his work almost entirely to a higher series, while the other has worked almost entirely on a lower series, so that discrepancies may be found in the structure contouring if the two series are not parallel-that is, if they converge in any direction. Over most of the area allowance has been made for such convergences as have been detected, but there 
are a few localities where the extent and direction of the convergence can only be surmised. Under such circumstances any attempt to modify the structure mapping by one geologist on a higher series to make it conform exactly with that done by another on a converging lower series is not justifiable. Accordingly, in certain areas there is not an absolute tie between the contours drawn by different observers, although everywhere the contours represent the geologic structure shown by the most readily traceable outcropping beds. To insure continuity in the structure contouring throughout several townships, some conveniently practicable datum plane, assumed to be parallel to the exposed strata, is chosen for the whole area considered, and the readings on the key rocks are projected to and plotted on this plane, which may be above or below the key rocks actually surveyed in the different townships.

Toward the west, where successively younger formations cover the principal oil sands more deeply, these sands are less likely to be parallel to the exposed strata on account of unconformities and convergences due to slight deformation or uplift of the rocks at different intervening stages. Hence the structure as interpreted from the exposed beds may depart more widely from that of the deep sands than it does farther east, where the sands lie nearer to the surface.

Evaluation of geologic structure.-The discussions of the structure are confined to those practical questions which are most important to the oil prospector. The conclusions advanced with respect to the merits of the folds represent the best judgment of the geologists as to the promise of oil and gas and as to the positions and depths of the sands from which production is expected. Nevertheless, it should always be remembered that notwithstanding the general productivity of the anticlines and domes, or, conversely, the relative rarity in this region of really favorable folds that are totally barren, only the drill can determine the ultimate question as to whether oil is actually present at any locality. Sands may be lenticular, tight, or even absent; anticlines in deep sands may not conform in position or form to those in the exposed beds; and possibly other features unobserved or not yet understood by the petroleum geologist may cause disappointment to the prospector.

The recommendations as to points favorable for initial wells to test undrilled areas are to be regarded as suggestions offered with the explicit understanding that dry holes at these places will not condemn the folds. Other tests at points rather less favorable theoretically may bring success, as in sec. 17, T. 25 N., R. 11 E. Even in regions where, as in the Osage Reservation, most of the oil pools are associated with anticlines or domes, few of them occupy the whole of the promising area of the fold. This circumstance appears in most places to be due to irregularity in the sand or lack of con- 
tinuity of the pay streak or to faulting which may have escaped discovery.

New oil reserves in Mississippian sands.-Both great economic importance and unusual geologic interest attach to the occurrence of oil in sands of Mississippian age in northeastern Oklahoma. Though some doubt exists as to whether the "Mississippi lime" is Boone or Pitkin, the important fact, emphasized by the writers of the following papers, is that oil is found at two or more horizons below the top of the Mississippian series. This fact, now generally recognized, points toward the discovery of new oil reserves in deeper sands be-

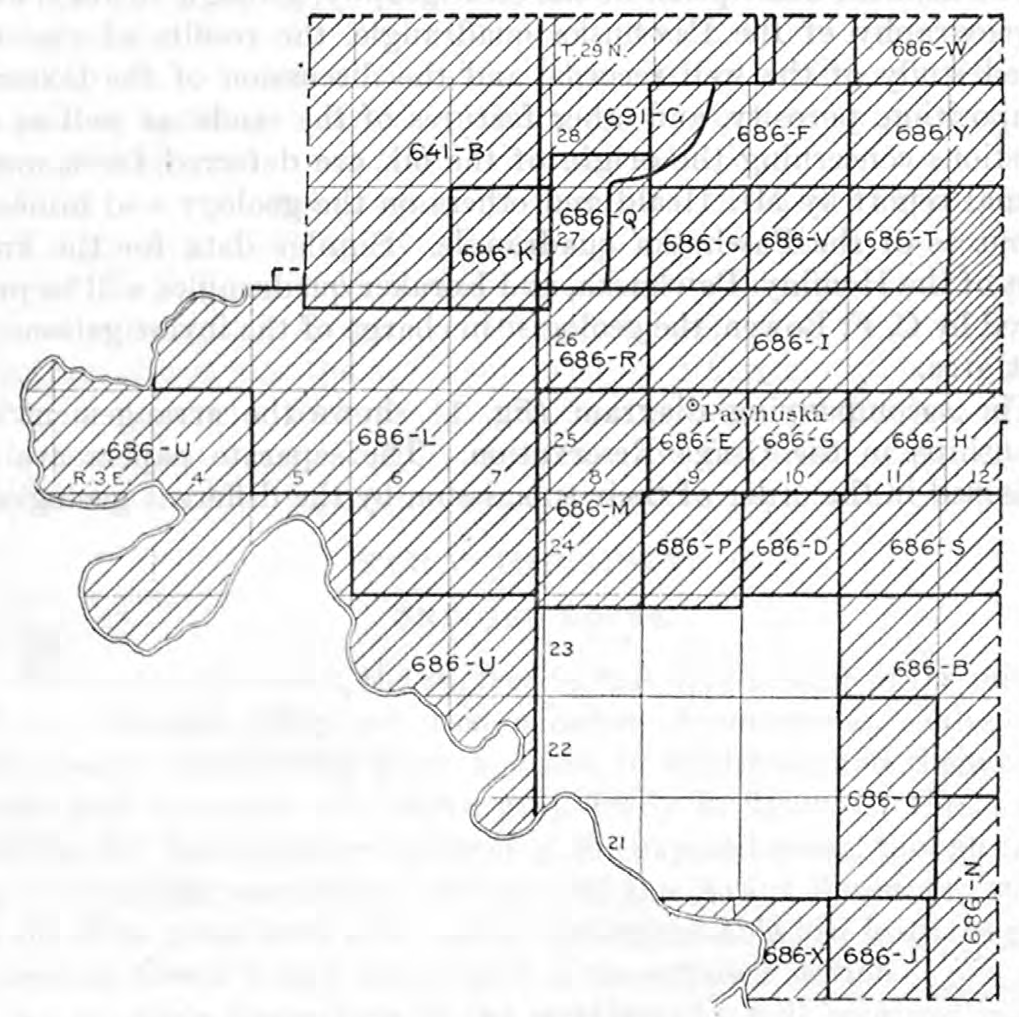

Figure 1.-Key map of Osage Reservation showing areas discussed in this and previous bulletins of the United States Geological Survey.

neath some of the producing pools, not only of the Osage Reservation but of the regions to the east, north, and south of it. Attention may be drawn also to the fact that the Sylamore (Devonian) sandstone, though patchy and local in its area of known development, may be present in portions of the oil field in this region. If present it offers oil possibilities, and it should be sought at a few points where anticlinal structure is strongly developed. 
Publication of full reports.- Some of the townships in the Osage Reservation have already been described with particular reference to their oil resources in the bulletins of this Survey, as already noted and as indicated in Plate I. These will not be described in this vol. ume. The townships lying west of R. 11 E. in the Hominy quadrangle are now being examined by Robert $\mathrm{H}$. Wood and, together with the remainder of the quadrangle, will be fully described in a bulletin now in preparation by $\mathrm{Mr}$. Wood. In the geologic mapping of this quadrangle the Oklahoma State Geological Survey has cooperated.

The detailed description of the stratigraphy, geologic history, and physiography of the Pawhuska quadrangle, the results of the detailed study of the well records, and the discuission of the texture, composition, porosity, and other features of the sands, as well as of questions concerning the origin of the oil, are deferred for a. more formal report by Mr. Heald and others on the geology and mineral resources of the Pawhuska quadrangle. Similar data for the area west of the Hominy, Pawhuska, and Foraker quadrangles will be prepared by C. F. Bowen, the geologist in charge of the investigations in that area.

The accompanying diagram (fig. 1) shows the arrangement of townships in the Osage Reservation. The separate papers are to be issued in the order of their submission by the different geologists. 